\title{
COMPARATIVE ADVANTAGE MAXIMIZING MODEL FOR HEDGE ETA AMID SMES
}

DOI: 10.17261/Pressacademia.2021.1457

JEFA- V.8-ISS.3-2021(1)-p.117-125

\section{Chung-Cheng Fuㄹ, Vicky Yu-Hsin Fu²}

${ }^{1}$ Chung-Hua University, Department of Management, Hsinchu 300110, Taiwan. mark.c.fu@gmail.com, ORCID: 0000-0002-8375-3109

${ }^{2}$ Kang-Chiao International School, MUN Conference, New Taipei City 231308, Taiwan. vickyfu@kcis.com.tw, ORCID: 0000-0002-3802-5217

\begin{tabular}{l}
\hline Date Received: May 5, 2021 Date Accepted: August 6, $2021 \quad$ open OAccess \\
\hline To cite this document \\
Fu, C. C., Fu, V.Y.,. (2021). Comparative advantage maximizing model for hedge eta amid SMEs. Journal of Economics, Finance and Accounting \\
(JEFA), 8(3), 117-125. \\
Permanent link to this document: $h$ http://doi.org/10.17261/Pressacademia.2021.1457 \\
Copyright: Published by PressAcademia and limited licensed re-use rights only.
\end{tabular}

\section{ABSTRACT}

Purpose- An index of eta shall realistically align and enhance on work order basis process in manufacturing, due to tough business in competition urging SMEs to smart comparative advantage. Once these improvements failed, could not heal existent chronic pandemic of efficiency or effectiveness either.

Methodology- The research contrasts both substantial endogenous and exogenous variables by the driver of scale ratio as well as a throughput yield index, reflects the timely outcome to identify and fuse both quantitative and qualitative together driven by OEE, which correspond with among performance index, availability index, and quality index, runs live attributive data of subcategory to understand OEE based on financeoutcome dimension and process-outcome dimension from original uploading points.

Findings- SMEs accounted over nighty percent in industry, using OEE as a metric to address future discounting in hazy rule. Therefore, fusing the latest information technology is vital in assisting current deviation on tractable, realistic, and applicable improvement, which finds out a way forward maximum comparative advantage that while plotting the flexibility associated by Edge Computing under Modules Driven Architecture. Conclusion- Focus means about making it simple. A model provides particular eta to optimize scheduled work order validly. One case study is employed to explain and benefit both OEE and ROI.

Keywords: Comparative advantage, ROI, OEE, VUCA, VIVO

JEL Codes: O47, D24, D81

\section{INTRODUCTION}

The scale index transformative potential will only be fully captured by a new and different regulatory framework situated at the nexus of data and digital identity. The data quality is meant to ensure that all data is accurate, complete, consistent and as up-todate as possible. The tremendous changes in manufacturing, and the recent pro-active stance of monitoring data transaction, may potentially combine to facilitate a transition from one regulatory model to another. According to Schumpeter (1934), "capitalist enterprise" and "technological progress" are "essentially one and the same thing". And "the economic efficiency of an economic allocation or outcome in the presence of externalities" by Coase (1937). SMEs are always seeking for new business opportunities. By doing things differently than others, in order to enhance and secure their comparative advantage over competitors, the entrepreneur has to make the difference anew and explore new innovative business ideas, processes management, and marketing strategies, and so on.

Recently firms have begun to decry instant message for greatly increasing complexity, sometimes making even trivial feature difficult to build under VUCA acronym of volatile, uncertain, complex and ambiguous (Bennett \& Lemoine, 2014). The creating resources balance needs SMEs to reach a point at which optimization no longer makes critical mass, such tasks require a flexible mechanism to be consistently identified and modeled to filter out the risk factor for dynamically allocation. Absolutely, emerging tools, applications and theories highlights the rising trends and studies in the user experience (UX), user interface (UI), 
and graphic users interface (GUI) management field (Joo, 2017). Which is the process of finding the combination of decision variables corresponding to the best performance of a system, evaluated through the output of a suitable simulation model in practice (Meloni et al., 2020). It is like a financial supervisor trying to run a business with sufficient and necessary indexes of Return on Investment (ROI), meets the best way to remove any ambiguity is to measure the key financial outcomes as shown as Du Pont formula (Bragg, 2020) in figure 1. While using OEE to ensure its optimization of resources, and further tracking to achieve the maximum comparative advantage.

\section{Figure 1: Du Pont Formula}

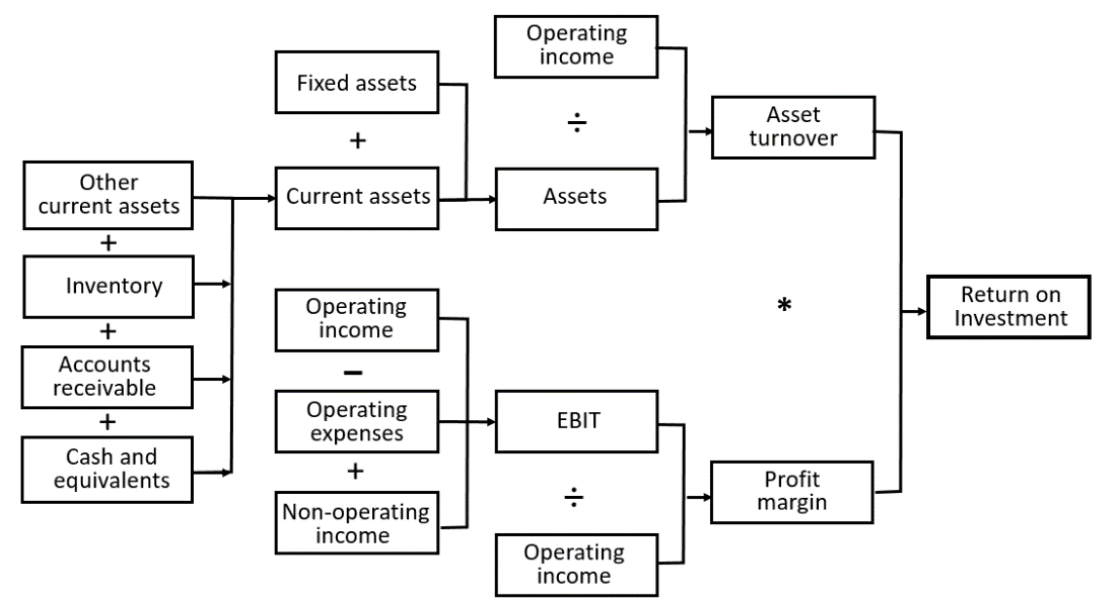

The paperless smooth process needs a tractable tool in front of origins at data input, which approaches infinite data acquisition, relies on upon well down of data flow continually with Online Transaction Processing (OLTP), which stands for batch processing, and provides Statement of Work (SOW), in-time result, and Decision Support System (DSS) under reliability and security. SMES have been using ERP workflow system, it belongs to finance-outcome dimension of structured data across various departments following subjective terms of SOP. On the other hand, MES shop-flow system belongs to process-outcome dimension driven by parameter, structured and unstructured data via Object-Oriented Techniques (OOT) with Online Analytical Processing (OLAP).

Figure 2: Data Uploading

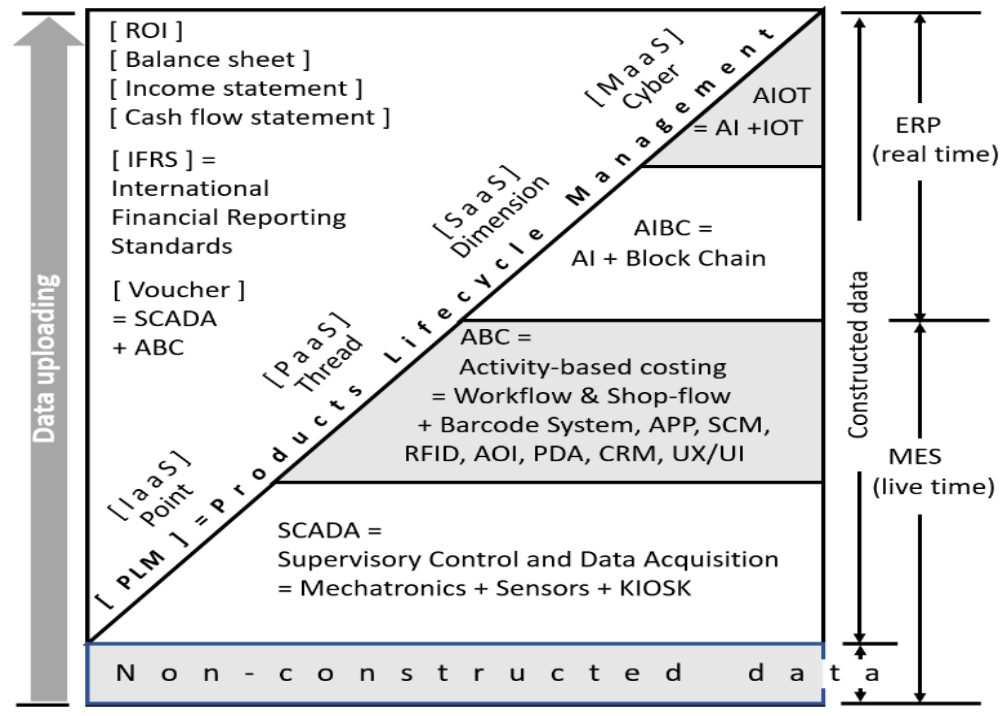

At the present time various services, products, and mobilizations as well as the latest tools and techniques are accessible and submission a lot of thoughts inside the custom-made modules (Sharma et al., 2018). Both concurrent data flow is seamless 
collaboration as data uploading as in figure 2, being linked and fed by live input with SCADA system (Block and Lindeber, 1990), such as sensors, barcode tools and mobile devices, and so on.

In developing amid data entry and digital transformation to open up an "observable" or "collaboration" pipeline at the same time, so that the authorities can understand what the processes are alert, what the operators are doing, and prevent majority of IT projects partially and completely fail (Standish, 2019). The Figure 2 shown as the right side is for manufacturing processes beginning at initial bottom line stepping up from Non-constructed data, SCADA, constructed data, ABC, AIBC, and until AIOT. The middle way of Figure 2 is a slop for Products Lifecycle Management (PLM) beginning at left moving along to right top thru Point of laaS, Thread of PaaS, Dimension of SaaS, and Cyber of XaaS, then archiving Mobility as a Service (MaaS). The left side of Figure 2 is finance procedure of IFRS going up thru Voucher, IFRS, Cash Flow Statement, Income Statement, Balance Sheet, and arriving ROI. Definitely, entire working elements and functions are conducted by Data Uploading under timely live OEE of MES module and liquidated ROI of ERP system.

There were lots of entry tools to improve data input and data uploading procedure onto narrowing digital divide, such as handy systems of barcode, QR code, AOI, RFID, Sensors, PDA, mobile APP, Device API, and so on. These entry tools and techniques are mature for application among machines, operators, processes, and API software. Definitely, wrong decision making derives from flawed data under GIGO (Vogt, 2005), because digits never lie. Saw another way, the output index of ROI usually cannot be any better than the quality of inputs except better outcome of OEE under collaboration amid ERP system and MES module as shown as Figure 3. There is a significant benefit to manufacturers while working and aligning to justify the scale ratio of proper Operating income and Operating expense under process capability index (Cpk).

Figure 3: Collaboration under ERP system and MES module

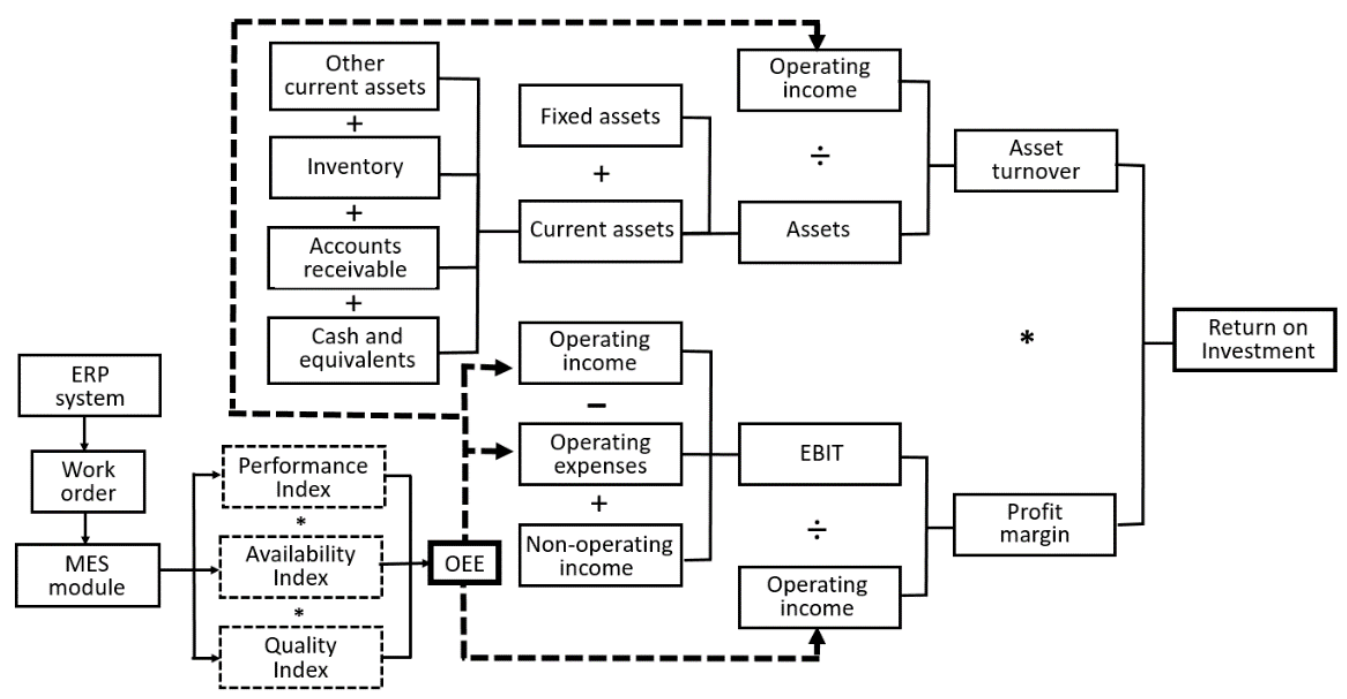

\section{LITERATURE REVIEW}

The empirical experiment model approach to the design of complex engineering and managing systems can be applied to social systems. The digital computer has become a practical, economical tool for the vast amount of computation required. These accomplishments now make it possible to cope with the greater complications that we find in the dynamics of industrial and economic behavior (Forrester, 1961). Data surveillance is now supplanting conventional surveillance techniques. With this trend come new monitoring and collecting online data such as mass dataveillance, it is going across various platforms (Clarke, 1988). Three types of system are identified and differentiated: mechanical, organismic, and social systems. The evolution of our concept of an enterprise from mechanical to social is then traced, including the consequences of (1) considering the parts of an enterprise separately, as is commonly done, that is, managing analytically versus synthetically; (2) supervising personnel who can do their jobs better than their bosses; (3) treating problems separately rather than systemically, and (4) taking disciplines as aspects of reality, that is, as categories of nature (Ackoff, 1994). The normal manufacturing system works itself. Over the whole range of production activity, supply is adjusted to demand by Production Control that is automatic, elastic and responsive under information technology. Lots of entries and applications are currently looking for both structure and accuracy of the data being 
fed into process to make assured outputs. Since the mid-1990s businesses approach ERP systems influential in improving productivity and profitability (Velcu, 2008). The specialization of consultants makes them more attractive to the implementation and user's relationship becomes crucial in the success of the ERP implementation (Khosrowpour, 2000). However, ERP systems are complex and costly, which makes the implementation process challenging. Since the market has become more competitive than before corresponding with Agency theory (Basu \& Lederer, 2004). With the latest MES tools, the information sharing inside a manufacturing system will be enhanced which will lead to a higher productivity and efficiency and an increased profit for the company (McClellan, 2001).

Information-theoretic approaches have been largely displaced by information processing methods, couple of examples of which are reviewed in the domains of memory and thinking (Baird, 1984). While using DuPont model to visualize the impact under OEE parallel calculation that manufacturing improvements can have on financial performance (Leroux, 2020). Edge Computing Model (ECM), which calls for processing the data at the edge of the network, edge computing has the potential to address the concerns of response time requirement (Shi et al., 2016). There are many types of model, High level business process model for example Porter's Value Chain, Task Level model for example the Organization Chart. In implementing the MES into the system of Workflow model to see the steps of work order done inside the enterprise in reaching an activity's goal. Especially handling snags of internal or external transactions related with SMEs, which is chosen as the main guideline because it is a systematic approach to execute a project effectively and efficiently in form of a framework under Dynamic Systems Development Method (DSDM), which is an agile software development approach, consists of five phases: feasibility study, business study, functional model iteration, design and build iteration, and implementation (Stapleton, 1997).

A scale ratio approach is upending side effect of chronic pandemic in manufacturing industry and marketing services based on simulation optimization as an alert under parameters in data acquisition. These include Performance assessment software, Availability dynamic acquisition software, and Quality modeling software, and so on. If an application is inherently misfit, it is the project manager's fault (PMI, 2017). However, even if an application is working properly and final data is flawed, the supervisor still gets the criticism on site. Frustrations of users between GIGO and QIQO (Techopedia, 2021), which is the work-orderorientation, application-friendly way of expressing why an output is approaching accurate under the goal of quality index.

\section{DATA AND METHOGOLOGY}

A mathematical model that is improved, and developed the OEE of individual work order by hedge eta in this chapter. Typically, the final model must be launched to balance and improve variable elements of work order. The model includes indexes of OEE as follows: Performance index, Availability index, and Quality index under qualified scale ratio of throughput yield index.

Figure 4: A Model of Module Cooperative Array Matrix

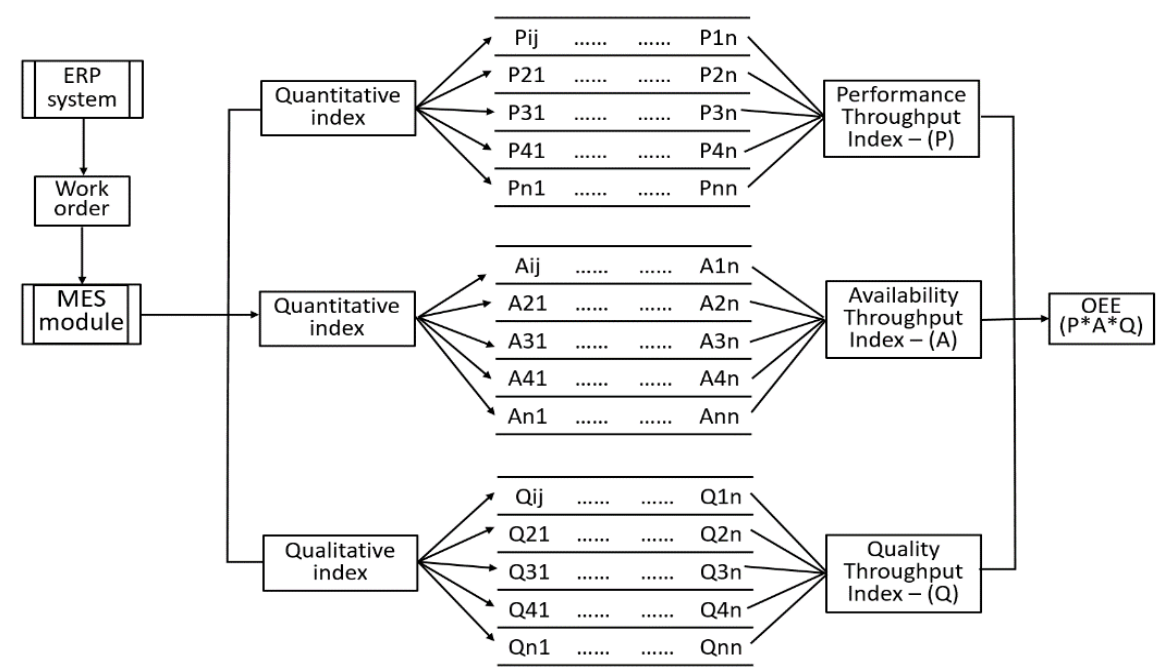

These three indexes of category normally are not full marks, account for speed losses as performance, downtime losses as availability, and defect losses as quality. If there is no losses any kind of sufficient conditions under flexible rolled management, then the OEE is $100 \%$. Establish an OEE necessary baseline, the existing formula is as below: 


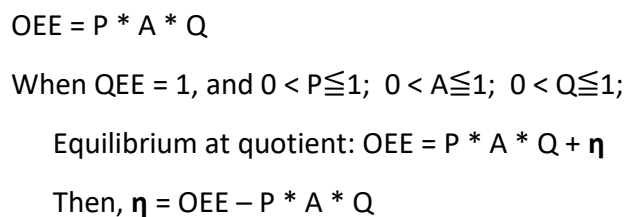

If there is nothing done so already, then review the hedge eta. Once the eta shows where the loss stands, work on the hedge eta, because it will put bucks on SMEs' bottom line and give a concrete numbers to justify additional balance improvements. A model for calculating the optimal eta coefficient can be constructed as:

$$
\begin{aligned}
& \text { Max } O E E=\sum_{j=1} \sum_{j=1} \sum p j q_{i j} \\
& \text { S.T. } \eta_{i}=O E E-\sum_{j=1} O E E_{i j} \quad i=1 \ldots m \\
& \sum_{i=1}^{m} \eta_{i} \leq z \\
& \text { aij }=f\left(q_{i j}\right) \\
& 0<q_{i j} \leq y_{i}
\end{aligned}
$$

Where OEE equal to 1 ;

$O E E=1$;

$\eta_{i}$, is the loss ratio of index of individual work order;

And, $\mathrm{z}$ is upper limit of the corresponding index of loss.

The $y i$ is upper limit of quality index.

\begin{tabular}{|c|c|c|c|c|c|c|c|c|c|c|c|c|c|c|c|c|c|c|c|}
\hline per- & $\begin{array}{l}\text { R } \\
\text { D }\end{array}$ & $\begin{array}{l}\mathrm{E} \\
\mathrm{C} \\
\mathrm{N}\end{array}$ & $\begin{array}{l}\text { B } \\
0 \\
M\end{array}$ & $\begin{array}{l}\mathrm{S} \\
\mathrm{C} \\
\mathrm{M}\end{array}$ & $\begin{array}{l}\mathbf{S} \\
0 \\
\mathbf{P}\end{array}$ & $\begin{array}{l}S \\
R \\
M\end{array}$ & $\begin{array}{c}M \\
S \\
A\end{array}$ & $\begin{array}{l}\mathrm{M} \\
/ \\
\mathrm{C}\end{array}$ & $\begin{array}{l}O \\
P\end{array}$ & $\begin{array}{l}0 \\
\mathrm{~J} \\
\mathrm{~T}\end{array}$ & $\begin{array}{c}P \\
L \\
M\end{array}$ & $\begin{array}{c}W \\
M \\
S\end{array}$ & $\begin{array}{l}\mathbf{F} \\
\mathbf{A} \\
\mathbf{I}\end{array}$ & $\begin{array}{l}\mathrm{I} \\
\mathrm{Q} \\
\mathrm{C}\end{array}$ & $\begin{array}{l}\mathrm{I} \\
\mathbf{P} \\
\mathbf{Q} \\
\mathrm{C}\end{array}$ & $\begin{array}{l}\mathbf{F} \\
\mathbf{Q} \\
\mathbf{C}\end{array}$ & $\begin{array}{l}0 \\
Q \\
A\end{array}$ & $\begin{array}{l}C \\
R \\
M\end{array}$ & $\begin{array}{l}\text { S } \\
\text { P } \\
\text { C }\end{array}$ \\
\hline PE & (0) & (0) & (O) & - & (O) & - & (0) & (0) & (C) & - & (0) & - & (0) & (0) & (0) & (0) & - & - & (O) \\
\hline $\mathrm{IE}$ & (0) & (1) & (0) & (0) & 0 & - & (0) & (0) & (0) & (0) & - & - & (0) & (0) & (0) & (0) & - & (0) & - \\
\hline PC & (O) & (0) & (0) & (0) & (O) & - & (0) & (0) & (0) & (O) & - & (O) & (0) & (0) & (O) & (O) & - & (O) & - \\
\hline Total & 3 & 3 & 3 & 2 & 3 & 0 & 3 & 3 & 3 & 2 & 1 & 1 & 3 & 3 & 3 & 3 & 0 & 2 & 1 \\
\hline Acc. & 0 & ? & ? & 0 & 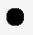 & & 0 & 0 & ? & 0 & & & 0 & 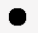 & 0 & 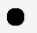 & & 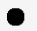 & \\
\hline
\end{tabular}

Using live OEE data gives related hard facts of work order which can demonstrate the constraints in individual production process. Actually, the SCADA and TQM have been doing well with data acquisition, which provides fast, reliable, and accurate feedback, these key monitor factors are critical success factors (CSFs) based on Delphi Method after data acquisition as shown as Table 1.

Table 1: Critical Success Factors based on Delphi Method

While CSFs of SMEs implementation are mature concepts and have received considerable attention for over a decade, and have very often focused on specific aspects of the implementation processes. Resultantly, there is (1) the experienced experts documented that encompasses all significant CSF considerations, and (2) the theoretical experts get into the important factors of successful implementation. These critical items of RD, ECN, BOM, SCM, and SOP stand for performance index, these critical items of MSA, M/C, OP, and OJT stand for availability index, these critical items of FAI, IQC, IPQC, FQC, and CRM stand for quality index. These critical items make overall maintenance easier, are backed up by edge computing of its MES module as shown as Figure 5 . Key monitor critical items from SCADA and TQM. 
Figure 5: Key Monitor Critical Items from SCADA

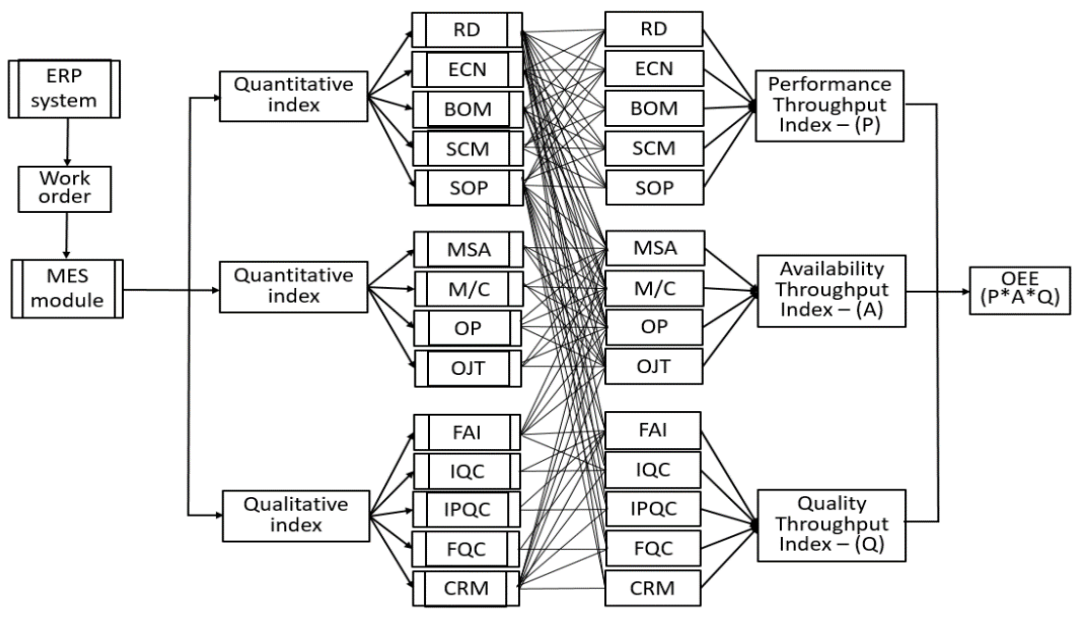

\section{FINDING AND DISCUSSION}

The effectiveness of the model proposed in this study is illustrated using a case study. The hypothetical work order of ERP can be concurrently executed by MES. Variances in costs as shown in Figure 6, plotting and indicating change in scale indexes of performance, availability, and quality. Such costs could include all of the cost elements which may have a trade-off against multilayer dependence and independence. This means all costs of every kind assembled to deliver the final product to ultimate users, including the cost of intangibles which affect perceived value. Furthermore, an accepted CSFs are qualified and approved factors for internal critical items of $\mathrm{P}, \mathrm{A}$, and $\mathrm{Q}$. For exploring the model of case maximum spaces, the work order of PD\#10301 follows the concept of simulation-based optimization.

\section{Figure 6: Qualified and Approved Critical Items}

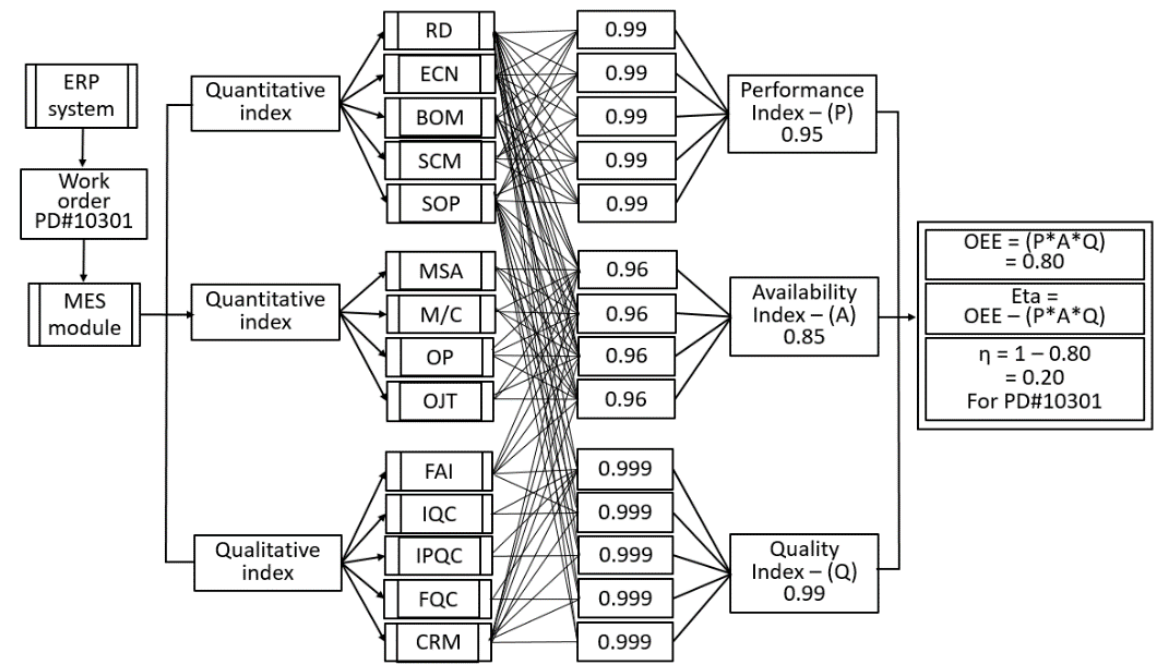

It combines the output of three hierarchical different outcomes to a kind of systematic enumeration of factor combination, the ratio of 0.99 fills out each critical item of performance at RD, ECN, BOM, SCM, SOP, and RTY of final performance index at 0.95; the ratio of 0.96 fills out each critical item of availability at MSA, M/C, OP, OJT, and RTY of final availability index at 0.85 ; in corresponding with $\pm 3 \delta$, the ratio of 0.999 fills out each critical item of quality at FAI, IQC, IPQC, FQC, CRM, and RTY of final quality index at 0.99 . Both OEE and Eta are the 0.80 and the 0.20 as shown as Figure 6. It shows that among these a search procedure based on the idea rolled throughput yield leads to the best results in this context. 
Continually, the model is fed by work order \#10302 that the performance critical item of 0.99 at RD, 0.97 at ECN, 0.99 at BOM, 0.95 at SCM, 0.99 at SOP, and RTY of performance index at 0.89 ; the availability critical item of 0.94 at MSA, 0.96 at M/C, 0.95 at $\mathrm{OP}, 0.91$ at OJT, and RTY of availability index at 0.78 ; the quality critical item in corresponding with $\pm 2 \delta$, the index of 0.999 at FAl, 0.98 at IQC, 0.98 at IPQC, 0.99 at FQC, 0.96 at CRM, and RTY of quality index at 0.91; both OEE and eta are the 0.63 and the 0.37 . And the \#10303 that the performance critical item of 0.96 at RD, 0.97 at ECN, 0.99 at BOM, 0.96 at SCM, 0.99 at SOP, and RTY of 0.88; the availability critical item of 0.95 at MSA, 0.96 at M/C, 0.96 at OP, 0.88 at OJT, and RTY of availability index of 0.77 ; the quality critical item in corresponding with $\pm 1 \delta$, the index of 0.99 at FAI, 0.98 at IQC, 0.96 at IPQC, 0.99 at FQC, 0.90 at CRM, and RTY of quality index of 0.83 ; both OEE and eta are the 0.56 and the 0.44 ; which creates work order \#10301, \#10302, and \#10303 different RTY, OEE, and Eta as shown as Table 2.

Table 2: Ratio of RTY, OEE and ETA

\begin{tabular}{|c|c|c|c|c|c|c|c|c|c|c|c|c|c|c|c|c|c|c|c|}
\hline \multirow{4}{*}{$\begin{array}{l}\text { CSF } \\
\text { Prod. } \\
\text { order }\end{array}$} & \multicolumn{6}{|c|}{$P(\%)$} & \multicolumn{5}{|c|}{$A(\%)$} & \multicolumn{6}{|c|}{ Q (\%) } & \multirow{4}{*}{$\begin{array}{l}\text { OEE } \\
(\%)\end{array}$} & \multirow{4}{*}{$\begin{array}{c}\eta \\
(\%)\end{array}$} \\
\hline & \multirow{3}{*}{$\begin{array}{l}\mathrm{R} \\
\mathrm{D}\end{array}$} & E & B & $S$ & $\mathrm{~S}$ & $\mathrm{R}$ & $M$ & $M$ & \multirow{3}{*}{$\begin{array}{l}\mathrm{O} \\
\mathrm{P}\end{array}$} & \multirow{3}{*}{$\begin{array}{l}\text { O } \\
\text { J } \\
T\end{array}$} & $\mathrm{R}$ & $\mathrm{F}$ & 1 & & & \multirow{3}{*}{$\begin{array}{l}\mathrm{C} \\
\mathrm{R} \\
\mathrm{M}\end{array}$} & \multirow{3}{*}{$\begin{array}{l}R \\
T \\
Y\end{array}$} & & \\
\hline & & C & 0 & C & 0 & $\mathrm{~T}$ & S & I & & & \multirow{2}{*}{$\begin{array}{l}\mathrm{n} \\
\mathrm{T} \\
\mathrm{Y}\end{array}$} & \multirow{2}{*}{$\begin{array}{l}\text { A } \\
\text { I }\end{array}$} & \multirow{2}{*}{$\begin{array}{l}\mathrm{Q} \\
\mathrm{C}\end{array}$} & \multirow{2}{*}{$\begin{array}{l}\mathrm{P} \\
\mathrm{Q} \\
\mathrm{C}\end{array}$} & \multirow{2}{*}{$\mathrm{Q}$} & & & & \\
\hline & & $\mathrm{N}$ & $M$ & $M$ & $P$ & $Y$ & A & C & & & & & & & & & & & \\
\hline 10301 & 99 & 99 & 99 & 99 & 99 & 95 & 96 & 96 & 96 & 96 & 85 & 999 & 999 & 999 & 999 & 999 & 99 & 80 & 20 \\
\hline 10302 & 99 & 97 & 99 & 95 & 99 & 89 & 94 & 96 & 95 & 91 & 78 & 999 & 98 & 98 & 99 & 96 & 91 & 63 & 37 \\
\hline 10303 & 96 & 97 & 99 & 96 & 99 & 88 & 95 & 96 & 96 & 88 & 77 & 99 & 98 & 96 & 99 & 90 & 83 & 56 & 44 \\
\hline
\end{tabular}

While lower RTY driving lower OEE, when SMEs see improvements in eta, these constraints are naturally being minimized. With these data in hand, supervisor can easily model the value of equipment, people, and process to improve final OEE and affiliated ROI. Improving OEE can help SMEs achieve all of these targets under reducing down time, waiting time, move time, queue time, setup time, and seven wastes. Because it is designed to review and improve operation efficiency and effectiveness as shown as Figure 7, as comparison simulation among three outcomes of $\mathrm{P}, \mathrm{A}$, and $\mathrm{Q}$.

Figure 7: Comparison Simulation among Three Outcomes of $P, A, \& Q$

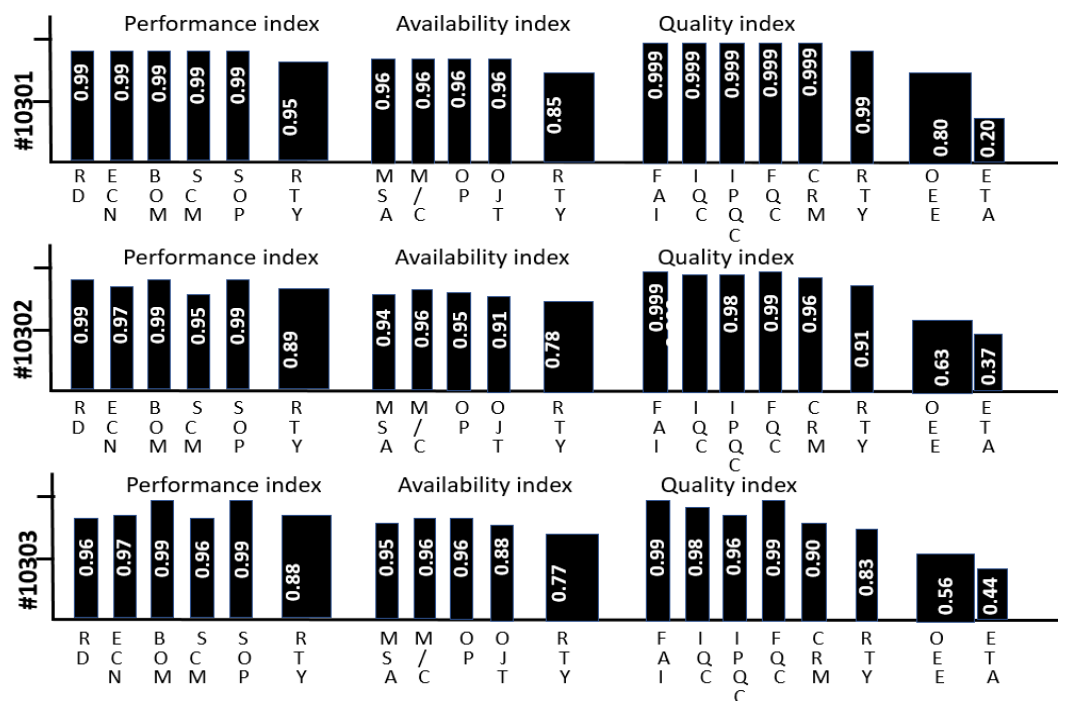

OEE is a lean manufacturing tool and universal best practice to monitor, alert, evaluate, and improve the efficiency of an operation process. These could be a research center, assembly line, machine cell, warehousing flow, packaging line, punching machine, logistics, and so on. Furthermore, by improving hedge eta in an ongoing quest to eliminate waste in every aspect, people improve 
most of the other critical manufacturing KPIs based on available trace and track system, including RD, ECN, BOM, SCM, SOP; MSA, $\mathrm{M} / \mathrm{C}$, OP, OJT; FAI, IQC, IPQC, FQC, and CRM, and so on.

Reasons why using OEE to understand the ROI of decisions is vital. For couples of years, ROI has been the primary means of justifying investment rationale as shown as Figure 8, Relationship among OEE, Hedge eta and ROI.

Figure 8: Relationship among OEE, Hedge ETA and ROI

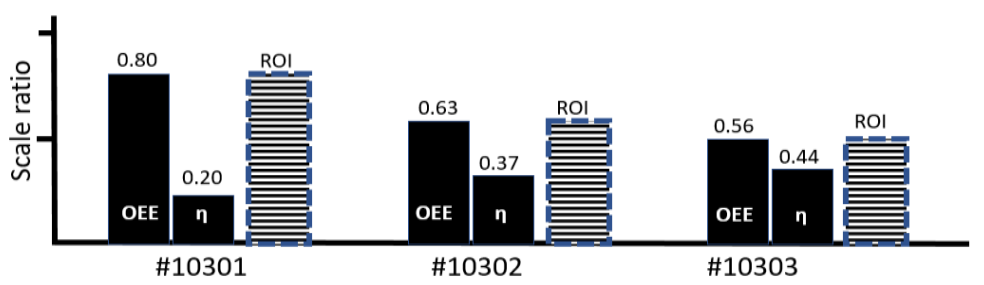

A kind of ratio change another kind of ratio follows change as shown as Figure 9 (1) and (2). The Figure 9 (1) that it represents an architecture of interconnection among $\mathrm{P}, \mathrm{A}, \mathrm{Q}$, and OEE. Typically, the Figure 9 (2) must follow the curve of marginal cost (MC) production definition, the MC-2 (marginal cost-2) should replace MC-1 (marginal cost-1) to last comparative advantage maximizing after aligning and improving of Eta. The ratio correlation between ROI and OEE is called positive proportional relationship. Conversely the ROI and Operating expense is called inverse proportional relationship as a connotation stand for ROI = OEE $/$ Operating expense, which corresponds with Economy of Scope yet.

Figure 9: (1) P, A, Q, OEE and (2) Operating expense, OEE, MC-1, MC-2, ETA and ROI
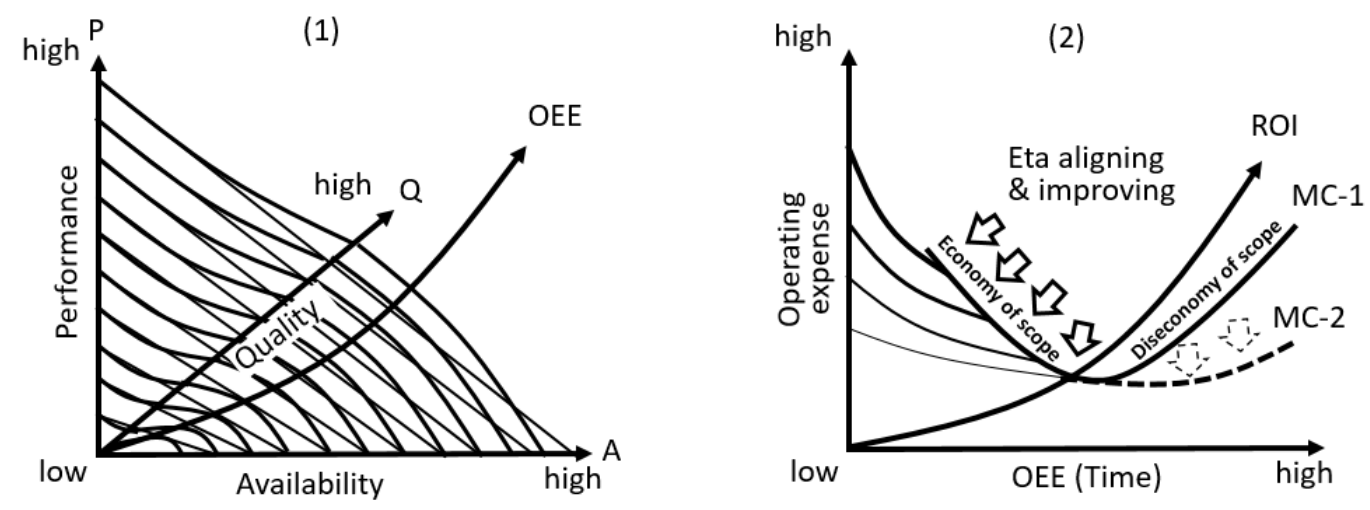

\section{CONCLUSION}

Focus means about making it simple. Sociable focuses in checking up outcomes of every work order and system module by observing changes in their state without being unequivocally customized. Solitary looks at prior probability between unstructured information entry automatically and changing structured operation procedure activities appropriately. The curable reason of data acquisition is to assemble calculations that can get input information and utilize factual investigation to foresee a systemic yield, while refreshing real idle time moves toward archiving the economy of scope on financial outcome as Value-in, Value-out (VIVO), which is a phrase that refers to the fact that the value of inputs simultaneously influences the value of the output under opportunity cost.

The introduction and adoption of simple eta allows us to monitor and audit current production data, which is replaced and aligned by at the assurance level under the prior probability, then displaying on e-dashboard, including live-time updated data transaction of machine, operator, automatic testing equipment, assembly line, quality inspection, and cash flow, etc. To do so, SMEs should consider the interiority at first, also a proposed front end of edge computing has by looking at improvements in flaw of each module. Once this kind of investigation is accomplished by eta, it may then determine the way which should mitigate the consequence of systemic collapse. With this new capability, SMEs can definitely reform the systemic risk and the diminishing marginal returns to correspond with the decision making method of live evaluating externality. 


\section{REFERENCES}

Ackoff Russell L. (1994). Systems thinking and thinking systems. System Dynamic Review, https://doi.org/10.1002/sdr.4260100206

Baird John C. (1984). Information theory and information processing. Information Processing \& Management, 20 (3), 373-381. https://doi.org/10.1016/0306-4573(84)90068-2

Basu, V., Leaderer, A.L., (2004). An agency theory model of ERP implementation. SIGMIS Conference. Tucson, AZ USA. DOI: $10.1145 / 982372.982375$

Bragg, S., (2020). Du Pont Analysis of Accounting Tools. Du Pont. https://www.accountingtools.com /articles/dupont-analysis.html

Bennett, N., Lemoine, G. J., (2014). What VUCA really means for you. Harvard Business Review, 92(1/2), 19-27.

Block, W. R., Lindeber, C. T., (1990). Project planning for EMS and SCADA systems. IEEE Transactions on Power Systems, 8(3), $151-159$.

Clarke, R., (1988). Information technology and data veillance. Communications of the ACM, 31(5), 348-355. https://doi.org/10.1145/42411.42413

Coase, R.H., (1937). The Nature of the Firm. Economic 4, November, 386-405. Brown, A.R., (2017), Utah, USA.

Foresster, J. W., (1961). Industrial Dynamics. The M.I.T. Press, Cambridge, Massachusetts, USA.

Joo, H., (2017). A study on understanding of UI and UX, and understanding of design according to user interface change. International Journal of Applied Engineering Research, 12(20), 9931-9935.

Khosrowpoue, M., (2000). Challenges of information technology management in the 21st century. Idea Group Publishing, Hershey, USA. http://www.idea-group.com

Leroux, M., (2020). OEE as a financial KPI, ABB. new.abb.com/cpm/production-optimization/oee-overall-equipment-effectiveness/oee-as-afinance-kpi

McClellan, M., (2001). Introduction to manufacturing execution systems. MES Solution Inc., 7-10, Oregon, USA.

Meloni, C., Pedrielli, G., Nieuwenhuyse, I. V., Xu, J., (2020). Simulation optimization in manufacturing and services. Flexible Services and Manufacturing Journal, 32(4), 763-766. DOI: 10.1007/s10696-020-09399-z

PMI (2017). A Guide to the Project Management Body of Knowledge (PMBOK Guide). 6th edition, USA. bigwords.com

Shi, W., Cao, J., Zhang, Q., Li, Y., Xu, L., (2016). Edge computing: vision and challenges. IEEE Internet of Things Journal, 3(5), 511-521. DOI:10.1109/JIOT.2016.2579198

Shcumpeter, J. A., (1934). The theory of economic development. Harvard Economic Studies, 664-678.

Sharma, T., Payal, M., Kaur, K., Dixit, P., (2018). An introduction to data warehousing and OLAP: pros \& cons. International Journal of Information Technology Insights \& Transformations, 2(2), 88-96.

Standish (2019). The Standish Group report 83.9\% of IT Projects Partially or Completely Fail. Standish Group, https://opendoor.bigroom.co/thestandish-group-report USA

Stapleton, J., (1997). Dynamic systems development method: the method in practice, 81, amazon.com.

Techopedia (2021). Definition - What does Quality in, quality out (QIQO) mean? Techopedia, https://www.techopedia.com/definition/ 28063/quality-in-quality-out-qiqo

Velcu, O., (2008). Drivers of ERP systems' business value. Swedish School of Economic and Business Administration. Edita Prima Ltd. Helsinik, Finland.

Vogt, W. P., (2005). Dictionary of statistics and methodology. Sage, DOI: 10.4135/9781412983907.n829 